\title{
Influência do Conceito Bobath na função muscular da paralisia cerebral quadriplégica espástica
}

\author{
Influence of Bobath's Concept on muscle function of the spastic tetraplegia cerebral palsy
}

Raine Costa Borba Firmino ${ }^{1}$, Ana Karolina Pontes de Lima², Cristiana Machado da Rosa e Silva Almeida ${ }^{3}$, Silvana Maria de Macêdo Uchôa ${ }^{4}$

\section{RESUMO}

Introduçáo. A Paralisia Cerebral (PC) é uma desordem que ocorre no Sistema Nervoso Central e interfere no funcionamento do sistema músculo esquelético. $\mathrm{O}$ conceito Bobath é baseado na neuroplasticidade e se utiliza da facilitação, normalização/adequação do tônus e reeducação do movimento, para auxiliar no desenvolvimento do movimento desejado. Objetivo. Avaliar a influência do Conceito Bobath na função muscular de um paciente com PC quadriplégica espástica. Método. Relato de caso sobre uma criança com PC quadriplégica espástica, realizado no período de novembro de 2013, nos Laboratórios da Universidade Católica de Pernambuco. O paciente foi submetido à avaliação clínica, física e análise cinético-funcional, através da eletromiografia, durante o repouso e a intervenção com os manuseios do Conceito Bobath (mobilizaçáo pélvica, alongamento do músculo iliopsoas e rotaçáo de tronco). Resultados. Pode-se observar, por meio da eletromiografia, que dentre todos os manuseios aplicados, houve uma maior ativação dos músculos oblíquo interno/transverso do abdome $(\mathrm{OI} / \mathrm{TrA})(34,1 \mu \mathrm{V})$ e paravertebrais $(38,7 \mu \mathrm{V})$ durante a mobilização pélvica para o lado direito. Conclusóes. Em uma única sessão, a análise eletromiográfica mostrou que a intervenção com os manuseios do Conceito Bobath pode apresentar benefícios na ativação de grupos musculares envolvidos no controle de tronco e no alinhamento postural.

Unitermos. Paralisia Cerebral, Postura, Fisioterapia

Citaçáo. Firmino RCB, Lima AKP, Almeida CMRS, Uchôa SMM. Influência do Conceito Bobath na função muscular da paralisia cerebral quadriplégica espástica.

Trabalho realizado na Universidade Católica de Pernambuco. Recife-PE, Brasil.

\section{ABSTRACT}

Introduction. Cerebral Palsy (PC) is a disorder that affects the Central Nervous System (CNS) and interferes in the musculoskeletal system normal functioning. The Bobath Concept relies on the neuroplasticity property, using tonus normalization and movement re education as tools to assist in developing the movement desired. Objective. To evaluate the Bobath Concept influence in the muscle function of a patient who had been diagnosed with spastic tetraplegia. Method. Case Study, with one child diagnosed with spastic tetraplegia, performed in november 2013, held in Universidade Católica de Pernambuco labs. The patient was submitted to an evaluation and a kinetic-functional analysis through an electromyography during rest and the session with handlings based on the Bobath Concept (pelvic mobilization, stretching the iliopsoas muscle and trunk rotation). Results. It was observed through the electromyography that among all applied handlings, there was higher activation on the internal oblique/ transversus abdominis $(\mathrm{OI} / \mathrm{Tr} \mathrm{A})(34.1 \mu \mathrm{V})$ and paravertebral $(38.7 \mu \mathrm{V})$ muscles during the pelvic mobilization to the right side. Conclusion. In a single session, the electromyography analysis revealed that the interventions by handlings based on the Bobath Concept may present benefits in the activation of muscle groups involved in the trunk control and postural alignment.

Keywords. Cerebral Palsy, Posture, Physical Therapy

Citation. Firmino RCB, Lima AKP, Almeida CMRS, Uchôa SMM. Influence of Bobath's Concept on muscle function of the spastic tetraplegia cerebral palsy.
1.Graduanda do Curso de Fisioterapia da Universidade Católica de Pernambuco, Recife-PE, Brasil.

2.Fisioterapeuta, Mestre, Docente Assistente I da Universidade Católica de Pernambuco. Recife-PE, Brasil.

3.Fisioterapeuta, Mestre, Docente Assistente I da Universidade Católica de Pernambuco. Recife-PE, Brasil.

4.Fisioterapeuta, Mestre, Docente Auxiliar da Universidade Católica de Pernambuco. Recife-PE, Brasil.
Endereço para correspondência Ana Karolina Pontes de Lima Praça do Derby, 63, apt. 301, Derby CEP 52010-210, Recife-PE, Brasil Email: ana.karolina.pontes@gmail.com 


\section{INTRODUÇÃO}

A Paralisia Cerebral (PC) também conhecida como Encefalopatia Crônica Não Progressiva da Infância, pode ser definida como um distúrbio crônico da postura e dos movimentos. Tal condição é persistente, mas variável, decorrente de uma desordem sem progressão que ocorre no encéfalo entre os períodos pré, peri ou pós-natal (até os dois primeiros anos de vida). Acontece na fase de maturação estrutural e funcional do encéfalo e, por isso, compromete as habilidades motoras da criança, o que pode impossibilitá-la de realizar movimentos e manter-se em posturas normais ${ }^{1}$.

A PC possui várias etiologias, dentre elas estão as malformaçōes do cérebro, problemas placentários, prematuridade, hipoxemia, fatores perinatais traumáticos, baixo peso do neonato e a anoxia grave ${ }^{2}$. Nos países em desenvolvimento, como o Brasil, estima-se que a cada 1.000 crianças nascidas, sete são portadoras de PC, sendo considerada a incapacidade física mais comum na infância. Esta condição pode estar relacionada com as más condiçóes de nutrição tanto materna quanto infantil, aos problemas gestacionais e à falta de atendimento médico e hospitalar adequado, principalmente nas classes sociais mais baixas ${ }^{3}$.

Segundo a Organização Mundial de Saúde (OMS), a PC interfere no funcionamento do sistema músculo esquelético, tendo como características distúrbios de tônus muscular, postura e da motricidade. Pode afetar várias partes do corpo e ser classificada, em relação à gravidade do comprometimento neuromotor, como leve, moderada ou severa. Em relação ao tônus muscular, pode ser do tipo espástico, atetóide, atáxico, hipotônico ou misto ${ }^{4}$; e de acordo com o nível de comprometimento neuromotor, em quadriplegia (acometimento dos quatro membros, sendo os superiores mais afetados), hemiplegia (acometimento do membro superior e inferior de um dos lados do corpo) e diplegia (acometimento dos membros inferiores e um mínimo comprometimento de membros superiores $)^{5,6}$.

A quadriplegia espástica é a forma mais grave da $\mathrm{PC}$, por comprometer tanto os membros inferiores como os superiores e ainda o tronco. Ela é caracterizada pelo aumento do tônus da musculatura extensora e adutora dos membros inferiores, flexora dos membros superiores e déficit na musculatura do tronco ${ }^{6,7}$. Existem vários músculos envolvidos no controle do tronco, entre eles estão os oblíquos internos e transverso do abdome (OI/TrA) e os paravertebrais. O comprometimento dessa musculatura reflete numa alteração do controle postural, que limita a realização de diversas atividades de vida diária (AVD's), o que interfere na independência do paciente ${ }^{8}$.

Existem vários métodos utilizados como forma de tratamento fisioterapêutico da PC que variam de acordo com o quadro clínico da criança, entre eles, o Conceito Bobath é um dos mais utilizados e focaliza a análise e tratamento de alterações sensório-motoras e funcionais ${ }^{9}$. Ele é baseado na neuroplasticidade e se utiliza da facilitação, normalização/adequação do tônus e reeducação do movimento, através de manuseios, em pontos chaves específicos, que ajudarão no desenvolvimento do movimento desejado. Porém, a criança precisa ter a capacidade perceptiva e cognitiva para o uso dessas habilidades e o sistema nervoso central (SNC) precisa adaptar-se a essas mudanças para que haja um bom desempenho nas atividades $^{10}$.

A eletromiografia de superfície (EMGs) é uma ferramenta de diagnóstico, utilizada na área de saúde para avaliar a atividade elétrica da musculatura. Ela apresenta vantagens em relação à EMG intramuscular, por não ser invasiva, ser simples e prática. É utilizada para diversas finalidades, dentre elas, verificar o comportamento neuromuscular em algumas patologias ou lesóes que afetem esse sistema e também o efeito da falta de uso da musculatura no nível da ativação muscular ${ }^{11}$.

Baseado no exposto, este estudo teve como objetivo avaliar a influência do Conceito Neuroevolutivo Bobath na função muscular de um paciente com PC quadriplégica espástica.

\section{MÉTODO}

\section{Amostra}

A presente pesquisa foi vinculada à Universidade Católica de Pernambuco (UNICAP), ao Centro de Ciências Biológicas e Saúde e ao curso de Fisioterapia, ligada ao projeto de pesquisa "Intervenção fisioterapêutica nas alteraçóes do desenvolvimento neuropsicomotor", sob no de CAAE: 09972713.7.0000.5206. Tratou-se de um estudo de caso, realizado no período de novembro de 2013 
nos Laboratórios de Fisioterapia e Terapia Ocupacional, Corpore Sano da UNICAP, localizados na Cidade do Recife-PE.

A amostra inicial foi selecionada por conveniência e consistiu de oito crianças com PC quadriplegia espástica que realizavam atendimento fisioterapêutico nos Laboratórios de Fisioterapia e Terapia Ocupacional, Corpore Sano da UNICAP. Teve como critério de exclusão as crianças que apresentavam alguma patologia associada à PC, incompatibilidade com o horário da pesquisadora, luxação de quadril, cognitivo alterado e aplicação de toxina botulínica em menos de três meses. A amostra final, então, resultou em uma criança.

\section{Procedimento}

Inicialmente foi realizado um primeiro contato com a criança e seu responsável para devida explicação sobre o projeto e assinatura do Termo de Consentimento Livre e Esclarecido (TCLE). Os mesmos foram informados de que sua participação seria voluntária, apresentando direito de desistir a qualquer momento.

No segundo contato, a criança foi submetida a uma ficha de avaliação, formulada pela pesquisadora, para traçar o perfil clínico, contendo dados como: nome, idade, sexo, raça, história do parto, peso e altura ao nascimento, complicações pós-nascimento, diagnóstico clínico e diagnóstico físico-funcional; seguida de uma ficha de avaliação física, onde foram analisados o padrão postural adotado, a presença de encurtamentos musculares e o controle de tronco. A criança também foi submetida a uma avaliação cinético-funcional através da eletromiografia para verificar a função muscular, onde foi utilizado o Biofeedback Eletromiográfico (Figura 1), de marca Mio$\mathrm{tec}^{\ominus}$, de quatro canais, que utiliza o software Miotool ${ }^{\oplus}$, com placa conversora analógico/digital de 14 bits de resolução para uma taxa de aquisição de $2000 \mathrm{~Hz}$ e mínima relação de rejeição de modo comum de $110 \mathrm{~dB}^{12}$. Para monitorar os músculos avaliados foram utilizados eletrodos de superfície descartáveis passivos com amplificador da marca Medi-trace Kendall-LTP (Figura 1).

Para o registro do sinal eletromiográfico, primeiramente foi realizado o procedimento da localização dos ventres musculares para colocação dos eletrodos, sendo os músculos avaliados: oblíquo interno/transver-
Figura 1. Biofeedback Eletromiográfico e Eletrodos de superfície da marca Medi-Trace Kendal LTP para eletromiografia.

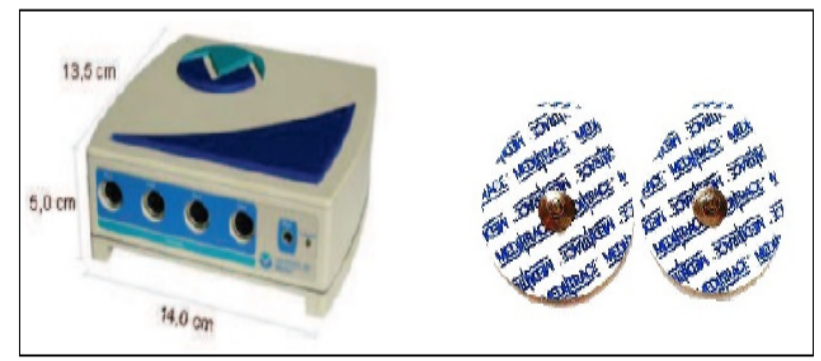

so do abdome (OI/TrA) e paravertebrais. A impedância elétrica da pele foi diminuída limpando-se o local com álcool a 70\%. A localizaçáo e a colocação dos eletrodos foram determinadas respeitando as recomendaçóes Surface Electromyography for the Non-Invasive Assessment of Muscles (SENIAM). Os eletrodos pertencentes ao canal 1 foram posicionados nos músculos paravertebrais, tomando como referência três centímetros do processo espinhoso de T9. A captação da atividade eletromiográfica dos músculos oblíquo interno e transverso do abdome foi denominada OI/TrA tomando como base o estudo no qual afirmaram que quando se avalia o músculo OI, através de EMG de superfície (EMGs), provavelmente estejam incluídos registros da atividade eletromiográfica provenientes do músculo $\operatorname{Tr} \mathrm{A}^{13}$. Os eletrodos do canal 2, então, foram posicionados tomando como referência a metade da distância entre um ponto localizado dois centímetros acima da espinha ilíaca ântero-superior (EIAS) e o púbis. Os canais 3 e 4 não precisaram ser utilizados. E o eletrodo de referência foi posicionado na espinha ilíaca ântero-superior (EIAS) direita ${ }^{12}$.

Para análise eletromiográfica durante o repouso, a criança foi posicionada na postura sentada no tablado, $\operatorname{com} 2 / 3$ da coxa apoiados, aproximadamente $90^{\circ}$ de flexão de quadril e joelho e os pés apoiados.

Os manuseios do Conceito Bobath foram realizados em uma única sessão e as repetições foram estabelecidas a partir do desempenho da criança. Foram utilizados: um tablado de $41 \mathrm{~cm}$ de altura, um apoio para os pés de $16 \mathrm{~cm}$ de altura e dois rolos de madeira: um maior de $32 \mathrm{~cm}$ de diâmetro e um menor de $22 \mathrm{~cm}$ de diâmetro. Para análise eletromiográfica, foram realizados os seguintes manuseios:

1.Mobilização pélvica: na postura deitada em decúbito 
vica no paciente, manuseada pela crista ilíaca esquerda e direita.

2.Alongamento do músculo iliopsoas: na posição de decúbito lateral sobre dois rolos, foi realizado o alongamento passivo dos músculos íliopsoas do membro inferior esquerdo (MIE) e direito (MID).

3. Rotação de tronco: na posição sentada no tablado com apoio para os pés, foi realizada a rotação do tronco de forma passiva pelo terapeuta para o lado esquerdo e direito.

O sinal eletromiográfico foi feito através da determinação da raiz quadrada média (Root Mean Square) e para o processamento desse sinal foram utilizados: filtro passa alta de $20 \mathrm{~Hz}$ e passa baixa de $500 \mathrm{~Hz}^{14}$. Foram registrados 15 segundos de contraçáo dos músculos paravertebrais e OI/TrA tanto no repouso como durante a realização dos manuseios do Conceito Bobath ${ }^{12}$.

$\mathrm{Na}$ etapa final do estudo, os resultados foram submetidos a uma análise descritiva, baseada na composição de tabelas ou gráficos. E para avaliar os dados obtidos durante os manuseios do Bobath, foram calculados os valores mínimo, média, máximo e desvio padrão da contração dos músculos paravertebrais e OI/TrA.

\section{RESULTADOS}

Nos Laboratórios Corpore Sano são atendidas 77 crianças no setor de fisioterapia. Neste universo, 28 crianças apresentam PC, dentre elas, 12 são diplégicas espásticas e oito são atetóides, por isso foram excluídas do trabalho. São classificadas como quadriplégicas espásticas oito crianças, dentre elas, sete se enquadravam nos critérios de exclusão e por isso foram impedidas de participar do estudo, conforme segue o organograma (Figura 2).

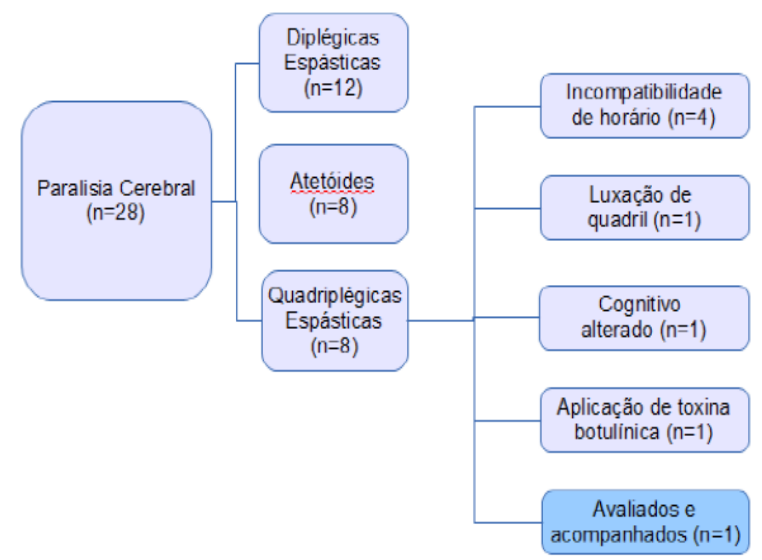

Figura 2. Organograma representativo da seleção de sujeitos conforme critérios de inclusão e exclusão.
A criança selecionada foi ELRG de sete anos de idade, sexo masculino, raça negra, com diagnóstico físico-funcional de quadriplegia espástica. O diagnóstico de PC foi realizado com menos de um mês de vida da criança. O parto foi normal, pré-termo (oito meses) e a criança nasceu com 2,970kg e $50 \mathrm{~cm}$ de altura. Após cinco dias de nascido, ficou internado na Unidade de Terapia Intensiva (UTI) durante oito dias devido à icterícia.

Devido aos comprometimentos causados pelas alteraçôes neurológicas e musculares, a criança apresentava padrão postural típico que consistia em flexão do cotovelo e punho, retroversão pélvica, encurtamento dos músculos quadríceps, iliopsoas tríceps sural e rotadores internos, escoliose (convexidade à esquerda e concavidade à direita), cifose torácica, além do déficit no controle tronco (fraqueza da musculatura abdominal e paravertebral), percebidos na avaliação física.

As médias dos músculos paravertebrais revelaram valores variando entre $19,1 \mu \mathrm{V}$ e $38,7 \mu \mathrm{V}$; e as dos músculos $\mathrm{OI} / \mathrm{TrA}$ variaram entre $5,4 \mu \mathrm{V}$ e $34,1 \mu \mathrm{V}$ (repouso e manuseios).

Os valores mínimo, média, máximo e desvio-padrão dos músculos paravertebrais e $\mathrm{OI} / \mathrm{TrA}$ foram registrados pela eletromiografia durante o repouso na posição sentada, a mobilizaçáo pélvica para o lado esquerdo e direito, o alongamento do músculo iliopsoas do MIE e MID e a rotação do tronco para o lado esquerdo e direito, apresentados na Tabela 1.

Observou-se que houve uma maior ativação dos músculos paravertebrais durante a mobilização pélvica para o lado direito $(38,7 \mu \mathrm{V})$, cujos registros dos sinais eletromiográficos estão demonstrados na Figura 3; e que houve o dobro do recrutamento de unidades/fibras motoras dos músculos $\mathrm{OI} / \mathrm{Tr} A$ durante a mobilização pélvica para o lado direito $(34,1 \mu \mathrm{V})$ se comparado ao lado esquerdo $(11,7 \mu \mathrm{V})$, cujos registros dos sinais eletromiográficos estão demonstrados na Figura 4.

\section{DISCUSSÃO}

As crianças com PC quadriplégica espástica dispôem de uma característica peculiar que é a presença de encurtamentos musculares, decorrentes da hipertonia, da falta de movimentação ou até mesmo do posicionamento incorreto quando sentadas. No estudo, a criança apresen- 
Tabela 1. Mínimo, média, máximo e desvio-padrão dos registros eletromiográficos (RMS em $\mu \mathrm{V}$ ) dos músculos paravertebrais (canal 1) e OI/TrA (canal 2) durante o repouso, a mobilização pélvica, o alongamento do músculo iliopsoas e a rotação do tronco.

\begin{tabular}{lcccc}
\hline Fontes de Variaçóes & $\begin{array}{c}\text { Mínimo } \\
\text { canal 1/canal 2 }\end{array}$ & $\begin{array}{c}\text { Média } \\
\text { canal 1/canal 2 }\end{array}$ & $\begin{array}{c}\text { Máximo } \\
\text { canal 1/canal 2 }\end{array}$ & $\begin{array}{c}\text { Desvio-padráo } \\
\text { canal 1/canal 2 }\end{array}$ \\
\hline Repouso & $3,0 / 0,6$ & $19,1 / 5,4$ & $133,3 / 40,9$ & $22,8 / 6,9$ \\
Mobilizaçáo pélvica para o lado esquerdo & $5,0 / 0,9$ & $33,4 / 11,7$ & $160,3 / 164,7$ & $21,9 / 11,3$ \\
Mobilizaçáo pélvica para o lado direito & $7,1 / 5,1$ & $38,7 / 34,1$ & $222,7 / 129,1$ & $24,6 / 13,2$ \\
Alongamento do músculo iliopsoas MIE & $7,9 / 7,1$ & $28,1 / 27,9$ & $139,3 / 81,6$ & $25,2 / 9,7$ \\
Alongamento do músculo iliopsoas MID & $5,8 / 4,5$ & $31,1 / 23,5$ & $152,2 / 87,1$ & $23,2 / 12,1$ \\
Rotaçáo do tronco para o lado esquerdo & $2,2 / 0,5$ & $15,8 / 7,7$ & $81,6 / 36,2$ & $15,9 / 5,7$ \\
Rotaçáo do tronco para o lado direito & $1,4 / 0,6$ & $20,8 / 8,8$ & $116,2 / 60,3$ & $20,4 / 8,9$ \\
\hline
\end{tabular}

RMS = raiz quadrada da média do sinal; $\mu \mathrm{V}=$ microvoltz; $\mathrm{MIE}=$ membro inferior esquerdo; $\mathrm{MID}=$ membro inferior direito.

ta encurtamento dos músculos iliopsoas, o que favorece a postura em flexão do quadril. Os encurtamentos musculares precisam ser abordados no tratamento fisioterapêutico devido à sua importância no sucesso da terapia e na facilitação da execução dos movimentos ${ }^{15}$.

A hipertonia está presente na maioria das crianças com PC e pode ser limitante na hora da realização de movimentos voluntários, além de resultar em posturas inadequadas ${ }^{16}$. A criança da presente pesquisa apresenta hipertonia global, o que a impossibilitava de realizar os movimentos voluntários dos membros superiores e inferiores, além de adotar postura de flexáo dos membros.

Uma das condutas utilizadas mais frequentemente no tratamento da hipertonia são os alongamentos musculares passivos, que visam reduzir as retraçóes e encurtamentos musculares ${ }^{17}$. No estudo, foram aplicados manuseios que visavam o alongamento do músculo iliopsoas, uma vez que essa musculatura se encontrava encurtada devido à hipertonia do paciente.

A espasticidade está presente na maioria das crianças com quadriplegia espástica e uma das formas utilizadas para inibição desta é a rotação de tronco ${ }^{18}$. A rotação de tronco é realizada através da contração dos oblíquos abdominais, porém é uma atividade que também exige a ação dos músculos antagonistas (paravertebrais) para a estabilização ${ }^{19}$. No estudo, foi visto uma ativação muito maior dos músculos paravertebrais em comparação aos OI/TrA durante a rotação de tronco para ambos os lados, corroborando com os estudos citados.

O controle postural é uma das funções mais importantes para as crianças com PC, essencial às posiçóes estáticas e dinâmicas, ligada às funçôes cerebelares. Al- guns músculos estão presentes na manutenção do equilíbrio postural, os chamados músculos axiais (tronco) e os apendiculares (proximais) ${ }^{20}$. Esse controle é responsável pela resistência à ação da gravidade e capacidade em manter o corpo em equilíbrio durante a realização de movimentos voluntários, onde são exigidos estabilidade dos membros, tronco e cabeça ${ }^{21}$.

Em geral, as crianças com PC quadriplégica espástica não dispóem de um bom controle de tronco e consequentemente da postura, devido às mudanças encontradas no mecanismo neural. Nessas crianças, a musculatura é afetada e a ativação inadequada desta altera o controle e equilíbrio corporal ${ }^{22}$. No presente estudo, pode-se observar um déficit de controle postural na criança analisada, o que a impedia de permanecer na postura sentada sem apoio e utilizar os membros superiores e inferiores, decorrente da má funcionalidade dos músculos do tronco e do mau posicionamento pélvico. A postura sentada permite que a criança exerça suas atividades de forma mais funcional, além de possibilitar o alcance aos membros superiores, o manuseio, a alimentação, etc ${ }^{23}$.

Outra característica presente em crianças com PC quadriplégica espástica é a diminuição da mobilidade pélvica, limitada pela hipertonia que pode gerar um aumento da inclinação anterior (hiperlordose lombar), uma inclinação posterior (cifose) ou uma inclinação lateral (escoliose), dificultando a movimentação ${ }^{21}$. A criança da presente pesquisa apresentava uma inclinaçáo posterior (cifose) e uma inclinação lateral (escoliose), decorrente desse mau alinhamento pélvico (retroversão pélvica). A posição e a movimentação da pelve são importantes para o controle postural, uma vez que influenciam no alinha- 
Figura 3. Registro eletromiográfico dos músculos paravertebrais durante o repouso e os manuseios do Conceito Bobath.

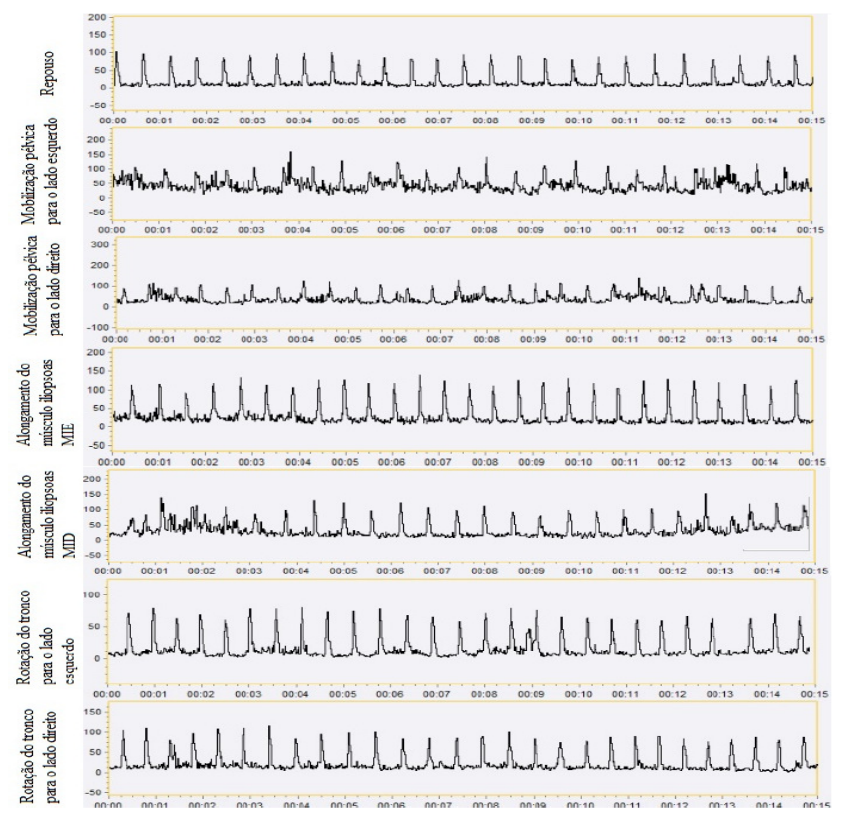

mento da coluna, da cabeça e dos membros (superiores e inferiores), facilitando o alinhamento postural para o equilíbrio ${ }^{23}$.

A intervenção aplicada ao participante do estudo foi baseada no conceito Bobath, que tem por finalidade incentivar e aumentar a habilidade da criança e promover respostas motoras automáticas, resultando em um controle funcional mais efetivo ${ }^{24}$. Os manuseios do Bobath aplicados influenciam o tônus muscular através da mobilização, alongamentos e ativação de músculos, partindo do princípio da manipulação de pontos-chave, o que facilita o controle postural e desempenho das AVD's ${ }^{25}$. A eletromiografia é usada para examinar a função muscular de forma quantitativa e estuda os fenômenos biolétricos que ocorrem nas fibras musculares durante o repouso e uma movimentação (mínima ou máxima) ${ }^{26}$. No presente estudo, foi percebido uma maior ativação muscular dos músculos paravertebrais e OI/TrA durante a mobilização pélvica. Esse fato pode justificar a contribuiçâo da mobilização pélvica para o controle da atividade muscular e a contribuição dos músculos OI/TrA e paravertebrais para a estabilização do tronco ${ }^{27}$.

Durante o registro eletromiográfico pode-se perceber que os músculos OI/TrA foram mais ativados durante a mobilização pélvica para o lado direito, quando comparadas as médias de ambos os lados. Este fato pode ser explicado pelo posicionamento do eletrodo de referência na EIAS do lado direito, ou ainda, pelo aumento da tensão muscular, no caso a escoliose presente no paciente, que gera um aumento de tensão para o lado daconcavidade. $\mathrm{O}$ posicionamento dos eletrodos como um dos fatores extrínsecos, e as características das unidades motoras (fibra muscular) e do tecido (gordura e temperatura corporal) como fatores intrínsecos, que podem causar interferências no sinal eletromiográfico ${ }^{11}$.

A partir da avaliação e resultado obtidos pela eletromiografia, observa-se a preservação das unidades motoras, o que revela a importância de se realizarem as mobilizaçóes, fundamentando-se a partir de umas das teorias do controle motor, que parte do princípio do feedback sensorial. Embora se saiba que a organização central de movimentos é a principal fonte do controle das funções motoras, é óbvio que a informação sensorial pode modificar esses comandos. O feedback sensorial contribui para o planejamento e execução da proposta, do objetivo e da direção do movimento. Dessa forma, áreas sensitivo-motoras do cérebro podem ser ativadas através dos manuseios propostos, a partir dos estímulos proprioceptivos, podendo reeducar a função motora perdida ou estimular a aquisição das que não foram aprendidas ${ }^{28}$.

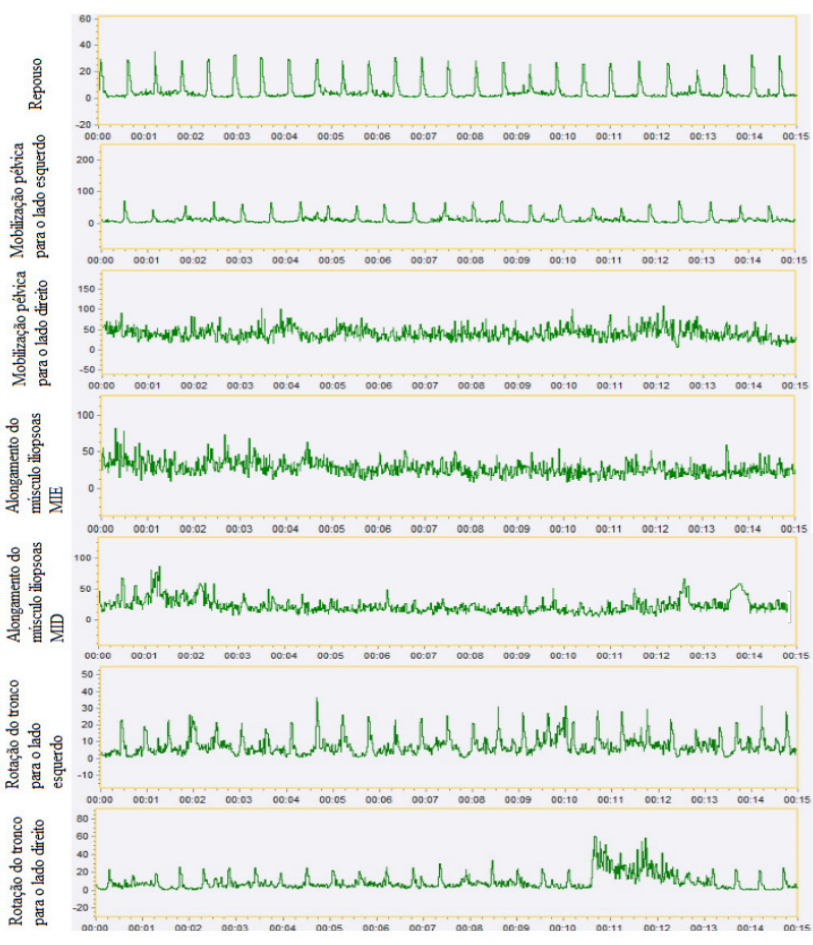

Figura 4. Registro eletromiográfico dos músculos OI/TrA durante o repouso e os manuseios do conceito Bobath. 
A ativação dos músculos do tronco pode proporcionar um melhor alinhamento postural, uma vez que as alteraçóes presentes no controle postural são devidas à dificuldade de ativação da musculatura de forma adequa$\mathrm{da}^{29}$. Este é um dado importante para que o tratamento seja traçado de forma mais eficaz em relação aos pacientes que dispõem de déficits de equilíbrio ou algum desalinhamento pélvico, assim como para a criança da presente pesquisa.

\section{CONCLUSÃO}

Os resultados obtidos na presente pesquisa revelam que através do Conceito Bobath, foi possível observar um recrutamento de fibras/unidades motoras, através da eletromiografia, com os manuseios escolhidos. Se em uma única sessão foi possível observar que os manuseios do Conceito Bobath apresentaram benefícios em relação à função muscular, acredita-se que se forem aplicados durante um maior período de tempo, possivelmente, haverá uma melhora em relação ao controle de tronco e ao alinhamento postural.

A análise eletromiográfica foi importante para a avaliação quantitativa da musculatura durante os manuseios e nos possibilita traçar novos objetivos e condutas, de acordo com a possibilidade de uma resposta muscular. Foram encontradas algumas limitações nesse estudo em relação ao tamanho da amostra, porém este trabalho contribui com a literatura relacionada ao tema. Sugerem-se mais pesquisas que envolvam a abordagem do Conceito Bobath e sua relevância na melhoria do controle de tronco em crianças com PC, através de estudos com um maior rigor científico.

\section{REFERÊNCIAS}

1.Peixoto ES, Mazzitelli C. Avaliação dos principais déficits e proposta de tratamento da aquisição motora rolar na paralisia cerebral. Rev Neurocienc 2004; 12:46-53.

2.Kavalco TF. A eficácia de orientaçóes de posicionamentos sentados funcionais aplicadas no domicílio para familiares de uma criança portadora de paralisia cerebral: um estudo de caso. (Trabalho de Conclusão de Curso). Cascavel: Universidade Estadual do Oeste do Paraná, 2003, 97p.

3.Camargos ACR, Lacerda TTB, Viana SO, Pinto LRA, Fonseca MLS. Avaliação da sobrecarga do cuidador de crianças com paralisia cerebral através da escala burden interview. Rev Bras Saude Mater Infant 2009;9:31-7. http:// dx.doi.org/10.1590/S1519-38292009000100004

4.Maranhão MVM. Anestesia e paralisia cerebral. Rev Bras Anestesiol 2005;55:680-702. http://dx.doi.org/10.1590/S0034-70942005000600012
5.Mancini MC, Alves ACM, Schaper C, Figueiredo EM, Sampaio RF, Coelho ZAC, et al. Gravidade da paralisia cerebral e desempenho funcional. Rev Bras Fisioter 2004;8:253-60.

6.Assis-Madeira EA, Carvalho SG. Paralisia cerebral e fatores de risco ao desenvolvimento motor: uma revisão teórica. Cad PG Dist Desenv 2009;9:142-63. 7.Castro CC, Batistela F, Martini G, Fonseca J, Montesanti L, Oliveira MC. Correlaçáo da função motora e o desempenho funcional nas atividades de auto-cuidado em grupo de crianças portadoras de paralisia cerebral. Med Reabil 2006;25:7-11.

8.Périco BC, Carvalho SMR, Braccialli LMP. Postura sentada de crianças com paralisia cerebral: influência do apoio dos membros superiores. Rev Cienc Med 2011;20:23-30.

9.Alcântara CB, Costa CMB, Lacerda HS. Tratamento Neuroevolutivo - Conceito Bobath. In: Cury VCR, Brandão MB. Reabilitação em paralisia cerebral. Rio de Janeiro: Medbook, 2011, p. 315-24.

10.Peres LW, Ruedell AM, Diamante C. Influência do Conceito Neuroevolutivo Bobath no tônus e força muscular e atividades funcionais estáticas e dinâmicas em pacientes diparéticos espásticos após paralisia cerebral. Rev Saúde 2009;35:28-33.

11. Correa CS, Costa R, Pinto RS. Utilizaçâo de diferentes técnicas para o controle do posicionamento dos eletrodos de superfície na coleta do sinal eletromiográfico. Rev Acta Bras Mov Hum 2012;2:5-13.

12.Assumpção MS, Piucco EC, Corrêa ECR, Ries LGK. Coativação, espasticidade, desempenho motor e funcional na paralisia cerebral. Motriz: Rev Educ Fis 2011;17:650-9. http://dx.doi.org/10.1590/S1980-65742011000400009 13.Sapsford R, Hodges PW, Richardson CA, Cooper DH, Markwell SJ, Jull GA. Co-activation of the abdominal and pelvic floor muscles during voluntary exercises. Neurourol Urodyn 2001;20:31-42. http://dx.doi.org/10.1002/1520-6777(2001)20:13.0.CO;2-P

14.Marques NR, Hallal CZ, Gonçalves G. Padrão de co-ativação dos músculos do tronco durante exercícios com haste oscilatória. Motriz: Rev Educ Fis 2012;18:245-52. http://dx.doi.org/10.1590/S1980-65742012000200004 15.Cargnin APM, Mazzitelli C. Proposta de tratamento fisioterapêutico para crianças portadoras de paralisia cerebral espástica, com ênfase nas alteraçóes musculoesqueléticas. Rev Neurocienc 2003;11:34-9.

16.Damiano D. Activity, activity, activity: rethinking our physical therapy approach to cerebral palsy. Phys Ther 2006;86:1534-40. http://dx.doi. org/10.2522/ptj.20050397

17.Santos LPD, Golin MO. Evolução motora de crianças com paralisia cerebral diparesia espástica. Rev Neurocienc 2013;21:184-92. http://dx.doi. org/10.4181/RNC.2013.21.808.9p

18.Zamberlan AL, Kerppers II. Mobilização neural como recurso fisioterapêutico na reabilitação de pacientes com acidente vascular encefálico - Revisão. Rev Salus-PR 2007;1:185-91.

19.Marcato FV. Análise dos ganhos funcionais de tronco no AVE após abordagem fisioterapêutica pelo Conceito Neuroevolutivo Bobath (Trabalho de Conclusão de Curso). Cascavel: Faculdade Assis Gurgacz, 2005, 82p.

20.Sakakura MT, Santos RB, Cyrillo FN, Perdigão AP, Torriani C. Análise comparativa eletromiográfica do músculo eretor lombar em pacientes com paralisia cerebral que tomam diferentes posiçōes sobre o cavalo. Brasília: Anais do XV Congresso Brasileiro de Equoterapia, 2006.

21.Sari FL, Marcon SS. Participação da família no trabalho fisioterapêutico em crianças com paralisia cerebral. Rev Bras Crescimento Desenvolv 2008;18:22939.

22.Bigongiari A. Ajustes posturais em crianças portadoras de paralisia cerebral (Dissertaçăo). São Paulo: Universidade São Judas Tadeu, 2006, 72p.

23. Borges MBS. Efeitos de um simulador de montaria no controle postural de crianças portadoras de paralisia cerebral (Tese). Brasília: Faculdade de Medicina 
da Universidade de Brasília, 2011, 66p.

24.Cury VCR, Mancini MC, Melo AP, Fonseca ST, Sampaio RF, Tirado MGA. Efeitos do uso de órtese na mobilidade funcional de crianças com paralisia cerebral. Rev Bras Fisioter 2006;10:67-74.

25. Gomes CO, Golin MO. Tratamento fisioterapêutico na paralisia cerebral tetraparesia espástica, segundo Conceito Bobath. Rev Neurocienc 2013;21:27885. http://dx.doi.org/10.4181/RNC.2013.21.757.8p

26.Tenório RMB. Utilização da eletromiografia de superfície na quantificação do tônus muscular flexor de recém-nascidos a termo e pré-termo (Dissertação).
Recife: Universidade Federal de Pernambuco, 2011, 35p.

27.Araújo PCS, Sá KN. Atividade eletromiográfica durante exercícios de estabilização dinâmica do tronco. Rev Cien Med Biol 2011;10:7-13.

28.Paula FVR, Faria CDCM, Vieira DSR. Teoria de programação motora: uma perspectiva de sua evolução teórica. Fisioter Mov 2007;20:63-71.

29.Espindula AP, Simóes M, Assis ISA, Fernandes M, Ferreira AA, Ferraz PF, et al. Análise eletromiográfica durante sessões de equoterapia em praticantes com paralisia cerebral. ConScientiae Saúde 2012;11:668-76. 